\title{
Are universities responding to the needs of students from refugee backgrounds?
}

Jaya Earnest
Curtin University
Andrew Joyce
Monash University
Gabriella de Mori
Curtin University
Genevieve Silvagni
Cardinia-Casey Community Health Service

A Ithough many Australian universities have been proactive in responding to students' diverse needs through orientation and support programs, very little is known about programs needed for the successful transition of students from refugee backgrounds into tertiary study. Facilitating the early engagement of students with their studies and campus life is linked to greater student satisfaction, improved retention rates and better educational outcomes. One of the challenges that academics face is the paucity of research on the learning styles and academic needs of African and Middle Eastern students from refugee backgrounds. This paper reports on a needs analysis undertaken with a group of students from refugee backgrounds in Victoria and Western Australia, using in-depth interviews and focus group discussions. Participants reported that current support systems and programs are inadequate or non-existent and that many feel disadvantaged compared to Australian-born and international students. The article concludes with recommendations on how universities can better respond to the needs of students from refugee backgrounds.

\section{Introduction}

The diversity of the current student body in higher education poses new challenges in regard to engagement of students from refugee backgrounds for whom the university may be a culturally alienating place (Krause et al., 2005). One of the challenges that academics face is the paucity of research in relation to students from refugee backgrounds in Australia; in particular, the absence of literature on the learning styles and academic needs of African and Middle Eastern students.

In the past decade, issues of student diversity have moved from the periphery to become central concerns of higher education institutions (Brown, 2004). Increasing globalisation presents new opportunities and challenges for higher 
education institutions internationally (Hanassab, 2006). Research indicates that facilitating the early engagement of students with their studies and campus life has shown to lead to greater student satisfaction and improved rates of retention (Krause et al., 2005). The challenge remains how to provide engagement opportunities to students from refugee backgrounds for whom the university culture in Australia is often a very foreign one.

This article reports on a study that was undertaken with students from refugee backgrounds from Africa and the Middle East who currently attend or have recently graduated from Curtin University of Technology in Western Australia and Monash University, Deakin University and the Royal Melbourne Institute of Technology (RMIT) in Victoria. Using a needs-analysis approach, the specific learning needs and educational experiences of this unique student cohort were ascertained and student-derived recommendations proposed to provide better support to students from refugee backgrounds.

\section{Background and theoretical underpinnings}

\section{Australian humanitarian intake}

Refugee migration to Australia in the last decade has two interesting trends that directly reflect enrolment patterns of students from refugee backgrounds in Australian universities. Refugee statistics in the last decade have been dominated by entrants from African backgrounds and by young entrants. In 2007-2008, a total of 10,799 resettlement visas were granted under the offshore component of Australia's Humanitarian program, comprising 6,004 Refugee visas and 4,795 Special Humanitarian Program visas (Department of Immigration and Citizenship, 2008). In this cohort of entrants, refugees from African countries comprised a total of 30.5 per cent of the total offshore intake.

From 2001 to 2006, African nations accounted for five out of the top 10 humanitarian group entrants to Australia, led each year except 2001 by Sudan. From 2002 to 2007, a total of 84 per cent of humanitarian visa entrants were between the ages of 16 and 35 years. Western Australia alone has settled 4,688 African humanitarian entrants between 2002 to 2006, with 60 per cent of these entrants under the age of 19 (Department of Immigration and Citizenship, 2008). From 2007 to 2008, immigration statistics changed dramatically, with Burma, Iran and Afghanistan comprising the highest visa intakes, a trend that may shift the profile of students from refugee backgrounds at universities in Australia over the next few years.

\section{Refugee youth in Australia}

The needs of refugee youth are complex and multifaceted requiring a coordinated approach among educational institutions, families, communities and service agencies. The results of the study by Earnest, Housen and Gillieatt (2007) revealed that educational institutions are the settings in which many of the hopes of refugee youth materialise. Young people from refugee backgrounds find educational institutions a safe environment; they enjoy learning and the routine that educational 
institutions provide. Australian and overseas literature highlight the importance of bringing health and social service providers into educational institutions, recognising educational institutions as a powerful resource for refugee youth and their families (Bond et al., 2007).

Recent Australian research has shown that students from disadvantaged backgrounds are confronted by a complex web of factors that influence students' decisions to withdraw from higher education (Joyce et al., 2010). Other studies have demonstrated that early engagement of students with their studies and campus community life can lead to greater psychosocial well-being, student satisfaction, better performance and improved retention rates within the university (Earnest, Housen \& Gillieatt, 2007; Silburn et al., 2010). Strong educational programs inclusive of educational staff, communities and families have been shown to increase psychosocial well-being and educational outcomes for students from refugee backgrounds (Silburn et al., 2010). The decision-making processes of refugee youth, the external influences regarding commencing and completing tertiary education in Australia and, in particular, the role that educational institutions can play in improving their adjustment and future outcomes need to be examined. Refugee youth continue to face challenges within the educational system, such as disrupted schooling and an inflexible education system within Australia that often affects future study and employment opportunities (Cassity \& Gow, 2005; Olliff \& Couch, 2005). There is limited research on the experiences of students from refugee backgrounds in Australian universities available to the tertiary education system.

\section{Diversity in tertiary institutions: Implications for educators}

Changes in the tertiary education sector have resulted in academic staff having to accommodate a higher proportion of students from diverse backgrounds, and tertiary institutions globally have been moving towards greater recognition and support of diverse student groups through bridging, foundation and fast-track programs. Educators in today's increasingly diverse learning environments need to recognise differences among students and promote effective communication, so that all students (including students from refugee backgrounds) gain competencies that assist them to successfully function in a pluralistic society (Northedge, 2003).

The establishment of appropriate cultural and social settings is an integral aspect of the learning process and assists in the realisation of an individual's learning potential and future goals and hopes. Multicultural and pluralistic nations require that particular attention be given to students with little experience in academic communities, who often struggle to develop an understanding of the expectations of academic culture. Their challenge is

to develop an effective voice through which to 'speak' the discourse, whether in writing or in class ... support in establishing voice is a vital component of courses for students from diverse backgrounds. (Northedge, 2003, p. 25)

There is evidence that effective educational practices, which facilitate students' engagement, provide a boost to under-represented and lower-achieving students commencing tertiary education. Data from the National Survey of 
Student Engagement conducted in 2006 found that student engagement activities fostering peer collaboration could assist in overcoming previous educational disadvantages (Wasley, 2006). The survey findings documented that there is a strong relationship between in-depth approaches to learning and self-reported gains in intellectual and social development (National Survey of Student Engagement Institute, 2006). Other studies have shown that early engagement of students with their studies and campus community life can lead to greater psychosocial wellbeing, student satisfaction, better performance and improved retention rates within the university (Krause et al., 2005; Tinto, 2004).

\section{Students from refugee backgrounds}

Although very little is known about refugee student perspectives, education needs, and their acculturation processes into university, the health needs of refugee young people and adults have been reviewed in the literature. Reviews of the health needs of refugees highlight the atrocities and adverse events they have experienced. These include the death of a close family member, injury and torture of family members, bombardments and shelling, detention, beatings, physical injury, disability inflicted by violence, sexual assault, disappearance of family members and friends, witnessing murder or massacre, terrorist attack, parental fear and panic, famine, forcible eviction, separation and forced migration (Burnett \& Peel, 2001; Davies \& Webb, 2000; Lustig et al., 2004).

Birman, Trickett and Vinokurov (2002) noted that, for students from this cohort, the acculturation process has three distinct aspects: language competence, behavioural participation and identification. These aspects are vital for successful outcomes at university as they allow individuals to communicate and function in differing contexts. Identity, in particular ethnic identity, is linked to psychological and psychosocial adjustment (Burnett \& Peel, 2001; Davies \& Webb, 2000).

For adolescent refugees, the educational environment is a key context for the development of language proficiency and identity. While a small percentage of this cohort successfully make the transition to university, students from this group very often find the multiple challenges of academic study, coupled with resettling in a host country and having to adjust to new belief systems, values and mores, too daunting. Currently, even though the numbers of students from refugee backgrounds (resettled in Australia on humanitarian visas) in universities is relatively small, this number is growing and educators need to be prepared to understand diversity in student intakes and provide the best possible opportunities for this cohort of students from refugee backgrounds.

\section{Refugee resettlement and educational experience}

Qualitative research has revealed a number of other barriers that refugee youth face in successfully completing secondary education. A large qualitative study of the social and emotional well-being of young people from culturally and linguistically diverse backgrounds in Australia found that the supportive roles young people take at home and issues related to disrupted or lack of education from their countries of origin made schooling in Australia very challenging (Brough et al., 
2003). Cassity and Gow confirmed this in their study with high school students from Southern Sudanese backgrounds living in Sydney (2005). The difficulties of little educational background and the pressures of supporting family here in Australia and in Sudan made schooling in Australia extremely difficult, decreasing the likelihood of successful transition to tertiary study that many refugee youth were hoping to undertake.

Preliminary research at Murdoch University in Western Australia showed that, in spite of relatively good levels of spoken English, many students from refugee backgrounds from Africa still experience difficulty with the transition into tertiary education. Some of the challenges identified include developing a more critical and reflexive learning style, applying meta-cognitive strategies, balancing learning with earning and adapting to Australian values and systems (Box, 2007). In recent years, the education system for refugees has tended to focus on English language and sports, with factors that greatly influence the students' performance and integration into the education system often ignored. These factors include issues of poverty, stress of resettlement, racism, discrimination and unemployment (Sidhu \& Taylor, 2007). These studies demonstrated that the learning and psychosocial needs of students extend far beyond the needs of adequate English language acquisition.

\section{Australian academic culture and its unfamiliarity}

Students from refugee and disadvantaged backgrounds frequently find the culture of tertiary institutions alienating, and experience difficulties in forming social bonds. The physical and social setting, including the teaching and support provided by the teacher, the behaviour of other students and the norms and expectations inherent in the setting are key aspects of this learning and teaching culture (Marini \& Genereux cited in Volet, 1999). These students, many of whom find universities a culturally alienating place, need to acquire the capacity to participate in the discourses of an unfamiliar knowledge community (Krause et al., 2005). Students who are under-prepared require a more specific tailored induction into the university and its knowledge communities so that they are strategically positioned and equipped to meet these challenges.

\section{Objectives of the study}

Our study had three main objectives:

- to examine, explore and interpret the perspectives and needs of students from refugee backgrounds engaged in tertiary education

- to document how these experiences influence personal educational outcomes and engagement with university life and culture

- to propose student-based recommendations to universities to improve and enhance outcomes for refugee youth.

\section{Research design}

\section{The qualitative approach and undertaking a needs analysis}

The culturally sensitive nature of the study led to an interpretive, qualitative approach being chosen (Denzin, Lincoln \& Smith, 2008). The qualitative approach 
allowed for shared dialogue between researchers and participants. We were able to draw attention to diverse perspectives, draw conclusions from a synthesis of the results and place the focus on the students' own perceptions, exploring the complexities and meanings of their experiences (Liamputtong \& Ezzy, 2005).

The study was conducted in Western Australia and Victoria and commenced with a needs analysis undertaken with refugee youth using focus group discussions and interviews. The 'voices' of the youth were captured to provide a rich and detailed account of their needs and experiences (Loizos, 2002). The needs analysis reported in this article was conducted in late 2007 and 2008 in Western Australia and in 2008 in Victoria to inform the development of a CD for academics and refugee youth to better support their needs. The needs analysis was used to identify problems, concerns and issues faced by students from refugee backgrounds, so that weaknesses could be considered. The needs analysis obtained qualitative information from students about their learning needs and their level of engagement with the university they attended. The final analysis facilitated a better understanding of the specific learning and social needs of students from refugee backgrounds and helped determine the factors that enable students to feel that they 'belong' to the university community (Cohen, Manion \& Morrison, 2000).

\section{Sampling and participant recruitment}

Participants were initially pooled from community contacts that the research team had previously established. At Curtin University, an initial list of students on humanitarian visas was obtained from the university's Office of Strategy and Planning. These potential participants were screened according to the selection criteria and asked for referrals to other potential participants if they were not eligible to participate in the study. Snowballing and purposive sampling from these initial contacts occurred thereafter. Very few refusals occurred, with most participants enjoying participating in the study and referring contacts to be included after the conclusion of their own interview.

The inclusion criteria sought participants who were currently enrolled or had recently graduated from Monash University, Deakin University or RMIT in Victoria, and Curtin University of Technology in Western Australia. Participants had to have come to Australia on humanitarian visas and were included regardless of age, course, gender, year of study, family structure, number of years in Australia, previous education or English proficiency before commencing tertiary education.

A total of 10 in-depth, semi-structured interviews were conducted with six male participants and four female participants from Sudan, Somalia, Afghanistan, Sierra Leone and Eritrea who attend Curtin University. Of these participants, seven were over and three were under the age of 25 years. The participants were studying education, health promotion, public health, commerce, environmental health science, engineering, nursing and social work. At Curtin University, all participants were undergraduate students.

Three focus group discussions were held with nine male and five female participants from Afghanistan and Oromia (one of nine ethnic divisions of Ethiopia) in Victoria. The participants in the focus groups were either currently attending 
university or had recently graduated from Monash University, Deakin University or RMIT. There was a mixed gender focus group for the Oromo participants and separate gender focus groups for the Afghan participants as this was preferred by the participants.

A cross-section of students from refugee backgrounds who varied in age, gender, ethnicity, religion, course, year level and family structure was included in the study. Prior to commencing university, participants had varying degrees of previous education, English language proficiency and computer literacy, all of which affected their experiences of university learning differently. Some participants had experienced the Australian educational system, including high school and TAFE qualifications. Others had studied in their countries of origin and entered education in Australia at tertiary level. Most participants experienced disrupted education due to experiences of war, seeking refuge in another country and resettlement in Australia.

\section{Interview and focus group discussions}

Semi-structured interviews and focus group discussions were used to explore the perceptions and experiences of the students from refugee backgrounds, and provided a rich and detailed set of data about thoughts, feelings and impressions in their own words (Liamputtong \& Ezzy, 2005). Pini (2002) noted that focus group discussions provide opportunities for reflection of the subjective experiences of everyday life. In both the interviews and focus group discussions, conversations flowed freely and participants were willing and felt supported to disclose their concerns about acculturation, resettlement, financial commitments, difficulties in obtaining suitable work and formation of new identities.

The semi-structured in-depth interviews and focus group discussions were guided by specific questions on topics such as background and demographics, general university life, university teaching environment, university social environment, university technology and administration systems, special psychosocial or emotional needs at university, coping strategies at university, and recommendations for future students. These questions explored aspects of the students' learning and engagement in university, feelings of connectedness to the university community, factors such as use of services and technology, and attendance at lectures and participation in tutorials. The focus group discussions and interviews were conducted at a time and place convenient to the participants. Interviews used open-ended questions and lasted 60 minutes. All interviews and focus group discussions were audio-recorded and transcribed.

\section{Ethical approval}

Ethics approval for the project was obtained from the Human Research Ethics office at Curtin University and the Standing Committee on Ethics in Research involving Humans through Monash University. Before starting their interview, participants were informed about the purpose of the study, informed consent was obtained and they were advised that they were free to withdraw from the study if necessary. 


\section{Thematic content analysis}

After the interviews were completed and transcribed, thematic content analysis was undertaken to collate and condense the information into distinct and succinct themes and recommendations that could be used to design and direct the remaining aims of the project (Boyatzis, 1998; Neuendorf, 2002). The aim of the analysis was to produce a succinct and reliable matrix of key themes (Reis \& Judd, 2000). This was important in communicating the results to participants as the summarised themes and recommendations were provided to participants for their feedback. The data analysis was guided by the framework approach to analysis (Pope, Ziebland \& Mays, 2000, Lacey \& Luff, 2001). There were four key stages:

- familiarisation-immersion in the raw data in order to list key ideas and recurrent themes

- identifying a thematic framework-identifying the key issues and the themes by which the data was examined and referenced

- indexing - applying the thematic framework to all the data in textual form by annotating the transcripts with codes

- interpretation-using the charts to define concepts, and find associations between themes with a view to providing explanations.

The themes and issues emerging from the analysis for each of the different groups of refugee youth were examined for similarities and differences and the distilled themes are presented in the results section. These themes were then subsequently used at Curtin University to develop and design a CD resource, which was trialled and evaluated in early 2009 .

\section{Results}

The thematic analysis from the interviews generated key themes relating to the educational experiences of the refugee youth. The themes explored the social, cultural and human contexts of refugee youth lives; the sense of community cohesion experienced as they resettled into Australia and their anxieties about the future (Earnest, Housen and Gillieatt, 2007). The students from refugee backgrounds openly voiced endemic financial difficulties, talked a great deal about worry and stress, as well as personal strength and resilience factors and how they tried to cope with their problems (Silburn et al., 2010; Earnest, de Mori \& Timler, 2010). The analysis, discussion and recommendations have considered issues of equity, hope, and social justice as the refugee youth interwove these within the stories of their lives (Hinton \& Earnest, 2010).

\section{Having a sense of direction}

Many of the participants described receiving mixed messages about enrolment, their qualifications and entrance requirements, which nearly forced them to give up on their dreams of tertiary education. Participants expressed feelings of having no support in their pursuit of beginning and completing their degree: 
To me the difficult part of getting to uni is the process of getting admitted ... when you try to use that qualification ... they completely rubbish it! I almost gave up studying ... It took me three and a half years to qualify to go to uni. (Sudanese male student)

They just say, you're not fit to be here, go back to TAFE and see what you can do from there ... When I went to TAFE ... they told me 'Your English is OK, you're not fit to be with us here'. (Sudanese male student)

\section{Preparation for university-negative and positive experiences}

There was a great difference in experiences and satisfaction with university for students who had completed at least some schooling in Australia or done a preparatory course before entering university, compared to those who had commenced directly into a degree program:

In relation to giving preparation classes for a year or so for refugees is actually, that is what is missing from councils and so many universities ... I studied in Russia for four years and before we went through anything in the classroom ... they introduced us to the language, they introduced us to their culture, even the basics, the day-to-day, how to greet woman, how to greet even to male. All those kind of things we went through in language school in Russia. And we studied for all this. (Oromo male student)

The students who had not received a preparatory course felt at a disadvantage compared to other students:

If you are by yourself and you are struggling to be competing with children who are born here and are writing, say, with the computers and everything. And then we start everything here. (Oromo female student)

Participants who had either spent a few years in high school or who had done a pre-university course believed that they were just as prepared as students who had completed all their schooling in Australia:

I was doing foundation studies last year which was really helpful ... It makes you ready for higher education. Like how to work there, how to give presentations, how to do assignments, how to study, how to write essays. It was all about that. (Afghan male student)

\section{Difference of teaching styles}

There are significant differences between the African, Afghan and Australian teaching styles. The African and Afghan teaching style was described as more teachercentred, with constant reminders to do work and to focus. No tutorials, group work or presentation assessments were involved, with the overall style described as 'spoon feeding', in contrast with descriptions of Australian universities' studentcentred teaching and learning approach, where students are forced to be more independent learners, do more individual research, are assessed in a variety of ways and need to be personally organised. Participants were often overwhelmed by the number of assessments they have to juggle with course work, in contrast with 
the end-of-year examinations they have been accustomed to. Consequently, they struggle to learn how to be disciplined with time management and to be selfmotivated. The new assessment and participation styles reveal that they have particular difficulty with meta-cognitive skills, critical thinking and academic writing:

The style of teaching is quite different ... here we find it every time, any topic you finish you need to be assessed on the topics, so you always have lots of assignments. It's not like you wait till the end of the semester and then you prepare for all, big exam working hard for 100 per cent, so here, that's one of the big difference. (Sudanese male student)

You have to be an independent person, you can't rely on teachers to tell you or for anything so, basically you have to be an individual, and independent and responsible ... that's what I know, but so far I haven't really learnt it. (Somali male student)

Once used to the system, some participants appreciated the variety in approaches:

Well, as the guys said that ... how hard and rigid the education system back in the country is ... when you're in Australia ... it's so much easier to study, you have more options ... if you get 50 per cent in an exam, [you can] do a really good essay and ... so it really gives you more opportunities. (Afghan male student)

\section{Education and learning}

The students had varying levels of education before commencing university. Most participants had experienced interrupted schooling. They were often the first in their families to obtain university degrees and felt a great sense of pride at this. Participants expressed difficulty in relation to academic writing and assessment, having had little or no experience in the system before starting tertiary study in Australia. There was a particular emphasis on unfamiliarity with essay and academic writing:

When I come to uni, I faced really big challenge which is the essay writing system ... the way you hand in your essay, the way you hand in your project, online project, I have never used a computer, for example, before. I can read the books, I do understand. But, understanding what I read and putting it together, and handing it to the lecturer. That is the problem. (Oromo male student)

I don't know that assignments exist back home. When I come out here, assignment is so difficult to write ... say I stay up to write a 2000 -word essay, I don't know what does that mean, what do they want? I used to think, like, I have to write like a book ... I just find out later you have to read and reference and you have to use ... [your] own words from discussion. From group work you get some right. (Oromo female student)

\section{English language competency}

Participants had varying years of experience speaking English, yet all had begun learning English before arriving in Australia. Despite this, participants felt that their 
English hindered them from participating in tutorials, as the discussion moved too fast for them to effectively understand:

Yeah, I found that, most difficult for me in English, the way you pronounce the words is different, so I was practising like all the time, so eventually I could speak it. (Somali male student)

Sometimes you can be there and putting all your attention, but you find the way this person speaks, you can't pick what you want. (Sudanese male student)

\section{Differences from non-refugee students}

The participants articulated their perceived differences from non-refugee students in a number of ways. One participant explained that students from refugee backgrounds are often learning four or five things at once, compared to non-refugee students who are solely focusing on the course work. For example, non-refugee students-who are not dealing with resettlement, acculturation and language problems-only have to learn the course work in class whereas a refugee student has to learn English, technology, communication and expected academic styles of assessment at the same time.

Refugee students were aware they had fewer personal support systems than other students who had well-established social networks and their families to support them. Participants felt they were at a disadvantage from their limited knowledge of Australian culture and history, and that courses were too focused on local Australian issues, not international topics that they were more familiar with and could contribute towards more in discussions:

Most people from refugee backgrounds haven't been to university before and they don't have anyone to give them advice or give them help at home. (Somali male student)

Because what happens is we have to learn two or three things at the same time ... Most people who are here and go to uni, they know they are going there to learn, but sometimes we go there to learn something from the class and also something of the lifestyle at the same time (Sudanese male student)

\section{Learning to navigate the web and use technology}

Participants found using the internet and computers the most challenging new skills to learn. Students consistently noted that the use of internet for research was the most difficult challenge to overcome at university. Other new skills such as academic writing, referencing and participation in tutorials were also important issues, but students were able to navigate these as the semesters progressed. Technology persisted as a confronting and frustrating challenge:

I don't know about computers, so my first year was really so hard ... locating resources on the internet, it's a major challenge for most of us who come from the developing countries. (Sudanese male student) 


\section{Use of campus services}

Although the Muslim students praised Curtin University for its Muslim services, such as the prayer room and availability of halal food, the other educational and support services at the university were not as frequently used. Despite teaching and learning support, counselling, health, equity, employment and social services being available - and which would be of great use to the students - many did not use the services and often found them culturally inappropriate. Participants were often unaware of these services and therefore did not access them:

Curtin is multicultural you know, everything, there's a lot of services for us like Muslims and international students ... there's a prayer area, halal places, you feel ... welcomed, you feel like you're home in a way. (Somali male student)

\section{Participation in university}

Students from refugee backgrounds were not as outspoken as other students in tutorials and group assignments, often feeling their contributions were not listened to or taken into consideration. They tended to remain quiet unless asked directly to participate. This was partly due to participants finding communication within the university system new and challenging, confounded by concern over their own levels of English, and a difficulty in contributing to Australian topics or feeling lost after an unfamiliar abbreviation or jargon was used or not explained. Participants also found making friends with Australian students difficult, making tutorial and group work participation unnerving:

I'll participate in class discussions, but sometimes the topics, it's something that I don't like or it's moved too fast and we can't get it. (Somali male student)

Sometimes you feel isolated. That's why ... I sometimes feel group work ... it's a waste of a time, because some people in my group may not want me to contribute. (Sudanese male student)

\section{Role of the university-academic staff and support systems}

Opinions of the quantity and quality of the services offered to students varied. For some participants, compared to experiences in their countries of origin or transition country, the teaching staff in Australia, were very supportive:

They're much more helpful here. They don't really care about your future there [Pakistan]. (Afghan female student)

Yeah, they're willing to help here. They're actually willing to give up their free time to help you with everything that you don't understand. (Afghan female student)

For other participants there was dissatisfaction at the level of understanding and empathy provided:

The uni can't relate to our experience. What background experience do we have? What, what challenges we came across ... No-one asked me just about my background. (Oromo male student) 
Cultural understanding of the students from refugee backgrounds and how they still have strong family connections back home that affects their everyday lives is a critical factor about which academic staff in Australia have little understanding. Understanding the particular experiences of students from refugee backgrounds was seen as a vital component that at times was not apparent and is poignantly revealed in a remark made by a female Oromo student:

Due to the corrupt government, for example, we have a lot of problem background which still comes to our class when we are sitting for lectures. So, the teacher or the lecturer ... never understand what we are going through ... It's not what we were going through, it's what we are going through today. For example, I hear the news from back home that someone is going to be confiscated, or, someone is going to be persecuted or hanged today, only because of political views from there. And then I have that news, and sitting for the lecture. And if I'm not attending, I'll be absent and will lose marks and a lot of things happening to you, but if I am there, only my body is there, my mind is not. (Oromo female student)

Participants felt that there was a general lack of understanding or awareness amongst academic staff concerning the issues that students from refugee backgrounds have faced before beginning study that influenced the academic performance. Some participants felt that they had experienced some form of prejudice from academic staff who assumed that students from refugee backgrounds possess basic or little knowledge, skills and education, despite some refugees having had degrees in their former countries. Although students from refugee backgrounds aren't familiar with some of the skills needed at Australian universities, they are highly capable of learning and adapting and should not be looked down upon as unable to grasp the new concepts:

There is a pre-mindset from the lecturer or it could be a teacher that ... he just presented that [topic] you can't understand or you are not capable of doing what is happening in the class, or what he is teaching. That is another problem too. (Oromo male student)

There was a difference for one of the participants studying international studies, where the university staff and fellow students showed a keen interest in this student's background, given its relevance to the course material:

Part of that is that ... in our area, international studies, everyone is aware of issues of refugees and immigration and, you know, human rights and problems overseas, and underdeveloped countries such as Afghanistan or Iraq or, you know, Africa ... so, for that reason everyone is so enthusiastic about knowing ... to know about your culture and problems and how can they help ... you know, they often ask you, 'How can I help you?' (Afghan male student)

The majority of the participants felt that student support does exist, particularly for academic writing, but many academic staff who facilitate these services often do not have a grasp of the specific subject material. Furthermore, the participants felt that these staff members do not allow adequate time in which students were able 
to effectively talk about and clarify their queries in relation to their essays and assignments. The support systems available varied between institutions, with a lack of consistency in the nature and delivery of programs:

One of the difficulties I have found, in universities, mainly is support. But in some cases, people who provide that support do not have any idea of the material that you present them. And sometimes, when you ask them some kind of terminology, whatever you present to them from your study in the class- the word from the book and the terminology you're using, they ask you back 'What do you mean by this?' . . . That's one of the difficulties I've found. (Oromo male student)

It is different for us, from uni to uni. There is one service that is drop-in. Just drop in. You have only about 15 minutes or so. But you have 3000 words, they just roughly go there 'OK, OK, OK' and then maybe they put a question mark and then they just go through what it is. But it is a big rush. Just 15 minutes to go through 3000 words is not easy. (Oromo male student)

Where there were specific programs offered by universities, the students considered that they were extremely beneficial:

We were assigned with a mentor, a volunteer student from university, who would show us around the library, how to use the catalogue, and if you have any problems you have to go to the counselling department, for special consideration or if you have problems with your assignments go to learning skills unit and they will support you. Things like that. (Afghan male student).

Compared to specific programs for students from disadvantaged backgrounds, participants who were only able to access generic language or academic writing support services found this to be ineffective and often cursory. Participants from only one of the universities that were represented in the focus groups and interviews were able to identify a support program or system that catered specifically to the needs of students from refugee backgrounds.

\section{Discussion and recommendations}

This article presents much-needed qualitative data that has previously been lacking in Australian literature on students from refugee backgrounds at university. As noted, there is a paucity of research on tertiary educational experiences of students from refugee backgrounds to date. Some preliminary research has been conducted (Box, 2007) but most focuses on refugee youth at high school in Australia. This study confirmed several issues highlighted in current refugee literature and contributed to the much-needed body of literature surrounding refugee students' experiences at tertiary education. Despite variation in the sample and the diverse and complex backgrounds particular to each student, the study drew succinct themes through the analysis that represented their voices and experiences from their own perspectives.

Students from refugee backgrounds, particularly those with limited educational experience, face a number of challenges coping with the demands of tertiary 
education in Australia. The experience of university is often overwhelming given the combination of stressors relative to resettlement issues and adapting to new educational settings. The journey, from arriving in Australia, to resettling and completing tertiary education is a long, arduous process that challenges the ambition, motivation and resilience of students from refugee backgrounds. Many of the participants in this study expressed a sense of anxiety and emotional distress due to carrying the burden of their refugee background, as well as anxieties and frustrations about the university culture and academic system; all of this was often compounded by real and overwhelming financial pressures and by issues that threatened the maintenance of their psychosocial well-being. Results from the study also confirmed that for many students from refugee backgrounds, university as a whole can be a culturally alienating place, further risking poor student engagement and affecting retention. In order to succeed, students are forced to quickly learn new academic skills in order to communicate and participate effectively (Northedge, 2003). The study documented the strategies and problemsolving methods that these resourceful students employed to develop into successful learners.

While there are existing services available for all students, including teaching and learning centres, life skills, counselling and employment services, these services remain underused and often students are unaware of them. Additionally, there are no specific tailored programs of induction into the university community and its services for students from refugee backgrounds. Programs and teaching methodologies may need to be developed that enable students to become active members of an initially foreign learning community and be empowered to develop a sense of belonging to this culture. Students who are academically under-prepared require a more specific tailored induction into the university and its knowledge communities so that they are strategically positioned and equipped to meet its challenges (Northedge, 2003). Supporting students to establish this voice is a vital component of success for students from diverse backgrounds.

\section{Student-derived recommendations}

Participants were asked in their interviews to suggest ways in which universities could better prepare and support them for university life, and what recommendations they would give to new students commencing university. Their responses were as follows:

\section{The need for guidance and encouragement to attend university} Participants stressed the need for guidance and encouragement to attend university, especially at high school. High school students need to be made aware of the possible courses to study and encouraged to have dreams and goals. They suggested reaching potential students through community and church groups and assisting with identified enrolment challenges. Interestingly, they also expressed a desire that their mothers and family members should also be encouraged to study and improve their English language skills and, if possible, gain additional professional qualifications. 
More attention and help especially in the first year at university Students from refugee backgrounds would like more attention and help, especially in first year. Participants felt lost and thought the lecturers were too busy, especially in first year units with so many students in each class. They suggested two lecturers in larger units, one to lecture, one to go around offering help. Participants also felt the need for increased, specialised, one-to-one academic and general support service for students from refugee backgrounds on campus. The support that students from refugee backgrounds needed was more than just language support and greater assistance with how to undertake, write assignments, use proper referencing and avoid plagiarism. They also felt that support and counselling staff need to have knowledge of the experiences of students from refugee backgrounds. They expressed a desire for increased interaction between academic staff and students from refugee backgrounds, and for cultural safety and awareness training to be provided to academic staff.

Offering students from refugee backgrounds a bridging course or preparatory course Participants felt that offering students from refugee backgrounds a bridging course or preparatory course before entering university would equip them with the necessary skills and knowledge of university culture and expectations. They also felt that their units should be more international in their focus, as universities must not assume all students are going to work in Australia upon graduation.

Increased financial support Lastly, the students discussed financial stress, and felt that more scholarships and financial assistance need to be made available for students from refugee backgrounds as a means to reduce stress and the temptation to discontinue their education for work. Most students were struggling to cope with the demands of supporting families back home, paying bills in time, and paying for their own personal needs (the rent, their fees and groceries).

These recommendations are further supported by recent studies by Earnest, de Mori and Timler (2010), Joyce and colleagues (2010) and Silburn and colleagues (2010) that proposed a need for understanding of refugee student issues, increasing academic awareness of refugee backgrounds and educational shortcomings (for example, poor English language skills, lack of continuous schooling and differences in learning styles) and implementing strategies to improve educational outcomes for students from refugee backgrounds that include mentoring, cultural sensitivity training for academics, participation in tutorials and involving students from refugee backgrounds in student guild activities.

\section{Conclusion}

These recommendations can both help frame future research into the academic needs of students from refugee backgrounds and also assist in the development of support programs. This study did not obtain information on the academic performance of students from refugee backgrounds and future research could track such progress. While participants did note that their experiences were not the same as international students, the aims of this study were not to compare the educational 
experiences between refugee and international students. But the refugee participants in this study who had completed some secondary schooling in Australia or completed a bridging course commented that they felt equal to Australian-born students in university readiness.

The participants included in the needs analysis varied in age, the courses they studied and the number of years they had been in Australia and at university. Their pre- and post-migration experiences that contributed to the stressors of resettlement and acculturation in Australia demand high levels of resilience and determination if they are to complete university education. In light of this, it is clear that the multifaceted needs of students from refugee backgrounds require a coordinated approach from university teaching and support staff that specifically deal with their needs. Despite these difficulties, this study has also revealed that universities represent the setting where many of the hopes of many of these students materialise.

Earnest, Housen \& Gillieatt (2007) noted that tertiary institutions need to develop new methods to impart the necessary skills and sensitivities for living successfully amid student diversity. Programs need to be developed that enable students to become active members of a learning community and have a sense of belonging to this culture. Students who are under-prepared (that is, who do not have an understanding of how universities operate and how to succeed within its culture) require a more specific tailored induction into the university culture and its knowledge communities so that they are equipped to meet its challenges and expectations (Northedge, 2003). Previous studies suggest that, given the challenges students from refugee backgrounds face at high school, university studies might be unrealistic for many students from refugee backgrounds (Cassity \& Gow, 2005; Olliff \& Couch, 2005). Participants of this study were extremely motivated and inspired to achieve their career objectives, and rated education as one of their top priorities.

The study has documented that there is a need for greater understanding to adequately respond to the needs of students from refugee backgrounds. This requires deeper cross-cultural awareness and avenues for communication so that students from refugee backgrounds become familiar with the expectations of their teachers and universities and vice versa. The results of the needs analysis have been used to specifically design and develop CDs for students from refugee backgrounds and for academics to enhance their understanding of the needs of students from refugee backgrounds. The CDs were trialled, evaluated and modified in the first semester of 2010 at Curtin University and will be made available to universities across Australia.

Although most students from refugee backgrounds had experienced disrupted schooling, multiple transitions before final resettlement in Australia and challenges associated with trauma and resettlement, all were confident that, with increased support, they would succeed at university and fulfil their aspirations. Future research on the needs of students from refugee backgrounds, together with the evaluation of support programs, could be of substantial benefit to students from refugee backgrounds and to universities in Australia. It is hoped that the voices and needs of students from refugee backgrounds in universities will be heard and their concerns dealt with so that they successfully complete university studies and 
encourage other youth who have come to Australia on humanitarian visas to commence tertiary education. Despite multiple difficulties in commencing and completing tertiary education, the dedication and resilience of these students to education is indisputable.

\section{Acknowledgements}

We would like to thank Healthway (the Western Australian Health Promotion Foundation) for funding the study. We also thank Ms Negah Rahmani for her assistance with data collection at Monash University. Last but not the least our thanks to the students from refugee backgrounds for sharing their experiences.

\section{Keywords}

refugee youth

psychosocial well-being

university student relationships

tertiary education

support systems

educational needs

\section{References}

Birman, D., Trickett, E. J., \& Vinokurov, A. (2002). Acculturation and adaptation of Soviet Jewish Refugee adolescents: Predictors of adjustment across life domains. American Journal of Community Psychology, 30(5), 585-607.

Bond, L., Giddens, A., Cosentino, A., Cook, M., Hoban, P., Haynes, A., Scaffidi, L., Dimovski, M., Cini, E., \& Glover, S. (2007). Changing cultures: enhancing mental health and wellbeing of refugee young people through education and training. Promotion and Education, 14(3), 143-149.

Box, G. (2007). Institutional Assessment Framework Report. Perth: Murdoch University.

Boyatzis, R. (1998). Transforming Qualitative Information. Thousand Oaks, CA: Sage.

Brough, M., Gorman, D., Ramirez, E., \& Westoby, P. (2003). Young refugees talk about well-being: A qualitative analysis of refugee youth mental health from three States. Australian Journal of Social Issues, 38(2), 193-209.

Brown, L. I. (2004). Diversity: The challenge for higher education. Race, ethnicity and education, 7, 21-34.

Burnett, A., \& Peel, M. (2001). Health needs of asylum seekers and refugees. British Medical Journal, 322, 544-547.

Cassity, E., \& Gow, G. (2005). Making up for lost time: The experiences of Southern Sudanese young refugees in high schools. Youth Studies Australia, 24(3), 51-55.

Cohen, L., Manion, L., \& Morrison, K. (2000). Research methods in education (5th ed.). London: RoutledgeFalmer.

Davies, M., \& Webb, E. (2000). Promoting the psychological well-being of refugee children. Clinical Child Psychology and Psychiatry, 5(4), 541-554.

Denzin, N., Lincoln, Y., \& Smith, L. T. (2008). Handbook of critical and indigenous methodologies. Thousand Oaks, CA: Sage.

Department of Immigration and Citizenship. (2008). Population Flows, Immigration Aspects 2006-07. Canberra: Department of Immigration and Citizenship, Program Statistics and Monitoring Section.

Earnest, J., de Mori, G., \& Timler, A. (2010). Strategies to enhance the well-being of students from refugee backgrounds in universities in Perth, Western Australia. Refereed report prepared for Healthway, the Western Australian Health Promotion Foundation. ISBN 978-0-646-53047-5. 
Earnest, J., Housen, T., \& Gillieatt, S. (2007). A new cohort of refugee students in Perth: Challenges for students and educators. Paper presented at the 16th Annual Teaching Learning Forum, University of Western Australia, Perth.

Hanassab, S. (2006). Diversity, international students, and perceived discrimination: Implications for educators and counselors. Journal of Studies in International Education, 10(2), 157-172.

Hinton, R., \& Earnest, J. (2010). Stressors, coping and social support among women in Papua New Guinea. Qualitative Health Research, 20(2), 224-238.

Joyce, A., Earnest, J., de Mori, G., \& Silvagni, G. (2010). The experiences of students from refugee backgrounds at universities: Reflections on the social, emotional and practical challenges. Journal of Refugee Studies. Retrieved from doi:10.1093/jrs/ feq001

Krause, K. L., Hartley, R., James, R., \& McInnis, C. (2005). The first year experience in Australian universities: Findings from a decade of national studies. Melbourne: Centre for the Study of Higher Education, University of Melbourne.

Lacey, N., \& Luff, D. (2001). Trent focus for research and development in primary health care: An introduction to qualitative data analysis. Sheffield, UK: Trent Focus Group.

Liamputtong, P., \& Ezzy, D. (2005). Qualitative research methods (2nd ed.). Melbourne: Oxford University Press.

Loizos, P. (2002). Misconceiving refugees? In R. K. Papadopoulos (Ed.), Therapeutic care for refugees. No place like home (pp. 41-56). London: Karnac.

Lustig, S., Kia-Keating, M., Grant Knight, W., Geltman, P., Ellis, H., Kinzie, J. D., et al. (2004). Review of child and adolescent refugee mental health. Journal of the American Academy of Child and Adolescent Psychiatry, 43, 24-37.

National Survey of Student Engagement Institute. (2006). National survey of student engagement. Electronic version. Retrieved 6 February 2006, from http://nsse.iub.edu/ NSSE_2006_Annual_Report/docs/NSSE_2006_Annual_Report.pdf

Neuendorf, K. (2002). The content analysis guidebook. Thousand Oaks, CA: Sage.

Northedge, A. (2003). Rethinking teaching in the context of diversity. Teaching in Higher Education, 8(1), 17-32.

Olliff, L., \& Couch, J. (2005). Pathways and pitfalls: The journey of refugee young people in and around the education system in Greater Dandenong, Victoria. Youth Studies Australia, 24(3).

Pini, B. (2002). Focus groups, feminist research and farm women: Opportunities for empowerment in rural social research. Journal of Rural Studies, 18(2), 339-351.

Pope, C., Ziebland, S., \& Mays, N. (2000), Qualitative research in health care: Analysing qualitative data. British Medical Journal, 320, 114-116.

Reis, H., \& Judd, C. (2000). Handbook of research: Methods in social and personality psychology. Cambridge: Cambridge University Press.

Sidhu, R., \& Taylor, S. (2007). Educational provision for refugee children in Australia: Left to chance? Journal of Sociology, 43(3), 283-300.

Silburn, J., Earnest, J., Butcher, L., \& de Mori, G. (2010). Learning interactively for engagement (LiFE) - Meeting the pedagogical needs of students from refugee backgrounds. Refereed Report prepared for the Australian Teaching and Learning Council, Canberra, Australia.

Tinto, V. (2004). Building programs for student success on campus. Paper presented at the 8th Pacific Rim First year in Higher Education Conference, Melbourne.

Volet, S. (1999). Learning across cultures: Appropriateness of knowledge transfer. International Journal of Educational Research, 31(7), 625-643. 
Wasley, P. (2006). Underrepresented students benefit most from 'engagement'. Chronicle of Higher Education. Retrieved 26 March 2007 from http://chronicle.com/free/v53/ i13/13a03901.htm

\section{Authors}

Jaya Earnest is Associate Professor and Postgraduate Research Coordinator in the Centre for International Health at Curtin University of Technology.

Email: j.earnest@curtin.edu.au

Andrew Joyce is a Lecturer in the Department of Health Social Science at Monash University and works with Southern Health as a health promotion worker for the Cardinia-Casey Community Health Service in Melbourne.

Gabriella de Mori is a Research Assistant in the Centre for International Health at Curtin University of Technology.

Genevieve Silvagni is a Health Promotion Practitioner at the Cardinia-Casey Community Health Service in Melbourne. 